\title{
Prende la computadora, usa el diccionario de colocaciones de sustantivo + verbo y mejora tu aprendizaje
}

\author{
Turn on the computer, use the collocation dictionary of verb + noun and improve \\ your learning
}

Ivonne J. de Mogendorff*

Cleci Regina Bevilacqua**

\begin{tabular}{|c|c|}
\hline $\begin{array}{l}\text { RESUMEN: Este trabajo presenta una } \\
\text { propuesta inicial de diccionario } \\
\text { pedagógico bilingüe de colocaciones } \\
\text { formadas por sustantivo + verbo en lengua } \\
\text { española. Su objetivo es auxiliar a los } \\
\text { alumnos de español, hablantes de } \\
\text { portugués brasilero, en sus producciones } \\
\text { orales y escritas. Estos estudiantes tienen } \\
\text { dificultad especial con aquellas } \\
\text { colocaciones en las que el verbo o el } \\
\text { sustantivo es diferente en las dos lenguas } \\
\text { como en "prender la computadora" } \\
\text { (español) y "ligar o computador" } \\
\text { (portugués) o "tener éxito" (español) y } \\
\text { "ter sucesso" (portugués). Los estudiantes, } \\
\text { generalmente no las trabajan de forma } \\
\text { clara y explícita en los niveles iniciales de } \\
\text { enseñanza, y por ese motivo, hacen la } \\
\text { transferencia de su lengua materna para el } \\
\text { español. Este trabajo aporta un panorama } \\
\text { general sobre la Fraseología, deslinda su } \\
\text { objeto de estudio y detalla las } \\
\text { características de las colocaciones. } \\
\text { Posteriormente, se expone la metodología } \\
\text { que se emplea para la selección de las }\end{array}$ & $\begin{array}{l}\text { ABSTRACT: This paper presents an } \\
\text { initial proposal of a collocation } \\
\text { pedagogical bilingual dictionary formed } \\
\text { by noun + verb, in Spanish language. Its } \\
\text { objective is to help Spanish learning } \\
\text { students, speakers of Brazilian } \\
\text { Portuguese, in their oral and written } \\
\text { productions. Those learners have special } \\
\text { collocation difficulty when verb or noun } \\
\text { is different in both languages as in } \\
\text { "prender la computadora" (Spanish) and } \\
\text { "ligar o computador" (Portuguese) or } \\
\text { "tener éxito" (Spanish) and "ter sucesso" } \\
\text { (Portuguese). Students will not usually } \\
\text { work them clearly and explicit at the } \\
\text { initial stages of learning, and therefore, } \\
\text { transfer their mother tongue to Spanish. This } \\
\text { paper provides a Phraseology picture, } \\
\text { identifies its object of study and outlines } \\
\text { collocation characteristics. Subsequently, } \\
\text { this study explains collocation selection } \\
\text { methodology and presents a proposal of a } \\
\text { collocation dictionary formed by } \\
\text { divergent noun + verb between both } \\
\text { languages. This dictionary is expected to }\end{array}$ \\
\hline
\end{tabular}

*Maestría en Literaturas de Lengua Española, Colégio de Aplicação/UFRGS. ivonne.jordan@hotmail.com

** Posdoctorado en Letras, Instituto de Letras/UFRGS. cleci.bevilacqua@ufrgs.br 
colocaciones y se presenta una propuesta de diccionario de colocaciones de sustantivo + verbo divergentes entre ambas lenguas. Se espera que este diccionario auxilie a los alumnos brasileros a mejorar su dominio colocacional $\mathrm{y}$, por ende, su competencia comunicativa.

PALABRAS CLAVE: Colocaciones. Lengua española. Aprendizaje. Diccionario pedagógico. En línea. help Brazilian students improve their collocation knowledge, as well as their communicative competence.

\section{Introducción}

Los estudiantes brasileños de lengua española presentan dificultades en la producción oral o escrita de las colocaciones debido a la interferencia lingüística del portugués. Esto se debe a que transfieren las combinaciones de su lengua materna a la lengua española por desconocer las unidades fraseológicas utilizadas en español.

En este trabajo pretendemos unir fraseología con lexicografía y proponer la confección de un diccionario pedagógico bilingüe en línea de colocaciones para la enseñanza de las colocaciones simples ${ }^{1}$ (formadas por dos unidades léxicas simples). A partir de las propuestas de Corpas Pastor (1996, p. 67-76) y Koike (2000, p. 41-42), estas colocaciones tienen la estructura de verbo + sustantivo, una de las categorías más representativas en número e importancia comunicativa (KOIKE, 2000, p. 3), especialmente cuando el sustantivo o el verbo utilizado en español es diferente al usado en portugués.

Nuestra experiencia en clase nos muestra casos como el de un alumno brasilero de $9^{o}$ año de la enseñanza formal cursando su segundo año de español que enuncia la siguiente frase: "Es mi cumpleaños, hoy quiero ganar un regalo y no tener aula". Si analizamos esta frase, desde el punto de vista gramatical y sintáctico, está correcta. Sin

\footnotetext{
${ }^{1}$ Koike (2000, p. 40) también registra las colocaciones complejas compuestas de una unidad léxica simple y una locución: por ejemplo: llorar a moco tendido, levantar castillos en el aire.
} 
embargo, un nativo de lengua española diría: quiero recibir un regalo y no tener clase. En la lengua española recibimos regalos, porque el verbo ganar no se usa con el sustantivo regalo, se gana una batalla, un juego, una competición o a la lotería. Y usamos clase para referirnos a la lección que imparte el profesor que se combina, en este caso, con el verbo tener.

Las combinaciones usuales en portugués brasilero son ganhar um presente y ter aula. El alumno, influenciado por su lengua materna, y con el conocimiento lexical de español correspondiente al segundo nivel de lengua española, se valió de su repertorio lingüístico para emitir estos enunciados. Las combinaciones recibir un regalo y tener clase son habitualmente enseñadas en un nivel inicial (Usuario Básico) de acuerdo con los Niveles Comunes de Referencia del Marco Común Europeo de Referencia para las lenguas (en adelante, MCER, CONSEJO DE EUROPA, 2002).

Es nuestro propósito que el alumno brasilero, con nivel Usuario Básico A2, esté capacitado para hablar o escribir sobre su rutina diaria, como en los ejemplos mencionados anteriormente, $\mathrm{o}$ en caso contrario, pueda aclarar sus dudas colocacionales de forma inmediata consultando un diccionario apropiado.

Estas estructuras a veces se incluyen en los manuales didácticos sin ningún llamado de atención, inseridas entre colocaciones que se construyen de forma igual en ambas lenguas. Como profesora de español de $8^{o}$ y $9^{o}$ año de escuela pública pude confirmar que los materiales didácticos distribuidos por el Ministerio de Educación del Brasil (como la colección Cercanía) incluyen vocabulario de apoyo y glosario bilingüe con listas de palabras traducidas al portugués que sirven para auxiliar en la comprensión de los textos; sin embargo, estas listas no contienen ninguna referencia a las colocaciones. 
Por ejemplo, en Cercanía $7^{2}$ (COIMBRA; CHAVES; ALBA, 2012, p. 14) aparecen en el mismo texto, sin ningún destaque, las colocaciones: me cepillo los dientes/escovo os dentes, me maquillo con un pintalabios/passo batom, voy a la escuela/vou para escola y llego a mi casa/chego em casa. Como no se resaltan las diferencias lexicales, el alumno no las interioriza y continúa teniendo la interferencia de su lengua materna al seleccionar el sustantivo o el verbo de la colocación en esta lengua, sobre todo en el momento de la producción en español.

Se constata, al analizar los recursos didácticos disponibles, que existe una preferencia generalizada en priorizar el aprendizaje de las estructuras gramaticales frente al aprendizaje del léxico. Sin embargo, el lingüista inglés Lewis (2002, p. 34) resalta la importancia del conocimiento del léxico en su dicotomía gramática/léxico al afirmar que: "la lengua consiste en léxico gramaticalizado y no gramática lexicalizada" ${ }^{3}$. Cuando se estudia una lengua extranjera no basta aprender la gramática y listas de palabras para comunicarse en la nueva lengua; por ese motivo, según este autor, hay que dedicar más tiempo a enseñar léxico que a enseñar gramática visto su relevancia para el desarrollo de la competencia comunicativa.

Cuando el hablante nativo se expresa, se vale intuitivamente de las colocaciones que son combinaciones de palabras, que se diferencian de las combinaciones libres porque tienen una cierta fijación interna, y de las locuciones porque son combinaciones con fijación en la norma y no en el sistema como estas últimas, conforme nos indica Corpas Pastor (1996):

La formación, el funcionamiento y el desarrollo del lenguaje están determinados no sólo por las reglas libres del sistema, sino también por todo tipo de estructuras prefabricadas de las que se sirven los hablantes en sus producciones lingüísticas. Dentro de este aspecto más

\footnotetext{
${ }^{2}$ Uno de los materiales didácticos usado en las escuelas públicas en Brasil, correspondiente a un nivel 2 de ELE.

${ }^{3}$ Texto original: "[...] language consists of grammaticalized lexis, not lexicalized grammar". Todas las citas son traducción de las autoras.
} 
fijo tienen cabida las combinaciones estables de palabras, muy generalizadas en la lengua, y de importancia capital en la adquisición y el procesamiento de la L1 (lengua materna) y la L2 (segunda lengua) (CORPAS PASTOR, 1996, p. 14).

Por ello, al utilizar frecuentemente ciertos patrones, una comunidad de hablantes termina por fijar determinadas combinaciones y las consagra como las más usuales. De acuerdo con Coseriu (1980), la norma de la lengua contiene todo lo que "es un hecho tradicional, común y constante [...] todo hecho que se dice y se entiende de esa manera y no de otro modo" ${ }^{4}$ (COSERIU, 1980, p. 122). Así, consideramos que es básico enseñarles estas combinaciones a los alumnos para que adquieran competencia en la lengua extranjera que están aprendiendo.

A partir de estas consideraciones y con el fin de auxiliar a los alumnos brasileros de Español como Lengua Extranjera (ELE), en sus niveles iniciales, iniciamos la elaboración un diccionario bilingüe de colocaciones formadas por sustantivo + verbo y que presentan divergencias entre el español y el portugués. Por ende, estas colocaciones "representan el grupo más numeroso y que mayor influencia tiene en la comunicación lingüística", según Írsula (1994, p. 281). El intuito es que los alumnos puedan buscar información de forma sencilla y autónoma, tanto dentro como fuera del aula, facilitando su producción lingüística e incrementando su competencia comunicativa.

Presentamos, en un primer momento, un breve panorama teórico sobre la Fraseología, su objeto de estudio y la definición y características de las colocaciones estudiadas. Posteriormente, explicamos los principios para la elaboración de un diccionario de colocaciones para aprendices y presentamos una propuesta de macro y microestructura iniciales del diccionario.

\footnotetext{
${ }^{4}$ Texto original: "[...] todo fato que se diz e se entende dessa maneira e não de outro modo."
} 


\section{La fraseología}

En el proceso de enseñanza y aprendizaje de Lengua Extranjera (LE) debemos enseñar cómo realmente se expresan los hablantes nativos para el desarrollo eficaz de la competencia discursiva y comunicativa de los educandos. La Fraseología es la disciplina que estudia toda la gama de combinaciones fijas, incluyendo las colocaciones, los modismos, los refranes, las expresiones de rutina, las locuciones, etc. Como afirma González Rey (2006, p. 124), “si consideramos la Fraseología de una lengua como aquella parte donde se fijan valores de la idiosincrasia de un pueblo, comprenderemos su importancia en la didáctica de esa lengua" ${ }^{5}$. En este sentido, el léxico de una lengua incluye combinaciones fijas que son establecidas por la tradición de su uso, de forma natural.

La importancia de esta disciplina está confirmada en el MCER, en su Capítulo 5.2.1.1 en donde se define la competencia léxica como "el conocimiento del vocabulario de una lengua y la capacidad para utilizarlo" e incluye dentro de los elementos léxicos “expresiones que se componen de palabras que habitualmente se utilizan juntas; por ejemplo: Cometer un crimen/error" (CONSEJO DE EUROPA, 2002, p. 108).

La Fraseología, según Navarro (2004), es un área en la que se unen la Lexicología, la Sintaxis, la Semántica y la Pragmática del Discurso y, por su complejidad, es difícil establecer sus límites. Por su parte, Ruiz Gurillo (1997) afirma que la fraseología está estructurada como un continuo difícil de separar, porque los límites en cuanto al comportamiento de sus miembros no son ni homogéneos, ni exactos.

El objeto de estudio de la Fraseología adopta varias denominaciones: expresiones pluriverbales, unidades léxicas pluriverbales, expresiones fijas, unidades

\footnotetext{
5 Texto original: "[...] se consideramos a fraseoloxía dunha lingua como aquela parte onde se fixan valores de idiosincrasia dun pobo, comprenderemos a súa importância na didática dessa língua."
} 
fraseológicas. Entre ellas elegimos el de Unidades Fraseológicas (UF) que, según Corpas Pastor (1996, p. 18-19), es el término que más se utiliza en las investigaciones sobre los sistemas fraseológicos de las lenguas. Esta autora define las UF como:

unidades léxicas formadas por más de dos palabras gráficas en su límite inferior, cuyo límite superior se sitúa en el nivel de la oración compuesta. Dichas unidades se caracterizan por su alta frecuencia de uso, y de coaparición de sus elementos integrantes; por su institucionalización, entendida en términos de fijación y especialización semántica; por su idiomaticidad y variación potenciales; así como por el grado en el cual se dan todos estos aspectos en los distintos tipos (CORPAS PASTOR, 1996, p. 20).

Estas combinaciones aparecen con una frecuencia de coocurrencia y de uso (en una muestra representativa de textos) superior a lo esperado según la frecuencia individual de cada palabra que permite su identificación (CORPAS PASTOR, 1996, p. 20-21). Debido a esta frecuencia, son institucionalizadas, lo que significa que son reconocidas por la comunidad de hablantes que las reproduce naturalmente (ídem, p. 21).

Esta autora (1996) presenta una clasificación del sistema fraseológico de la lengua española combinando el criterio de enunciado (acto de habla) con el de fijación (en la norma, en el sistema o en el habla de acuerdo con la tricotomía de COSERIU, 1980). Adoptamos la propuesta de la autora (ídem, p. 51) que define enunciado como “una unidad de comunicación mínima que corresponde generalmente a una oración simple o compuesta, pero también puede estar compuesta de un sintagma o una palabra".

Teniendo en cuenta esta combinación de criterios, las UF se dividen en dos grupos, considerando si aparecen o no de forma completa en el discurso. Así, a partir de la fijación del enunciado, la autora clasifica las UF en tres esferas: 
1) enunciado incompleto:

- Esfera I: UF fijadas sólo en la norma, sintagmas que han desarrollado algún grado de fijación debido a su uso. Son las COLOCACIONES: año fiscal, celebrar una reunión, dinero negro.

- Esfera II: UF del sistema. Son las LOCUCIONES: dar gato por liebre, vacas flacas, de pies a cabeza.

2) enunciado completo:

- Esfera III: actos de habla con fijación. Incluye las PAREMIAS, CITACIONES, REFRANES, FÓRMULAS RUTINARIAS: Vísteme despacio, que tengo prisa, Poderoso caballero es Don Dinero, Buenas tardes.

Las combinaciones: recibir un regalo y tener clase pertenecen, de acuerdo a la taxonomía anterior, a la Esfera I. Son enunciados incompletos, fijados en la norma, con algún grado de fijación y son clasificadas como COLOCACIONES. En el material lexicográfico didáctico que proponemos, nos ocuparemos de este tipo de combinaciones que "son elementos que entran dentro de la competencia de la semántica léxica del usuario, de su entendimiento de las relaciones internas de las palabras"6 (GONZALEZ REY, 2006, p. 132). Trataremos más detenidamente de este tipo de fraseología en el apartado siguiente.

\subsection{Las colocaciones}

Corpas Pastor (1996) define las colocaciones como:

unidades fraseológicas que, desde el punto de vista del sistema de la lengua, son sintagmas completamente libres, generados a partir de reglas, pero que, al mismo tiempo, presentan cierto grado de restricción combinatoria determinada por el uso (cierta fijación

\footnotetext{
${ }^{6}$ Texto original: "[...] son elementos que entran dentro da competencia da semántica léxica do usuario, do seu entendimiento das relacións internas das palabras".
} 
interna). Este rasgo esencial distingue las colocaciones de las combinaciones libres de palabras. (CORPAS PASTOR, 1996, p. 53).

Aunque las colocaciones son fácilmente comprensibles, pues pueden ser total o parcialmente transparentes, representan un obstáculo en el aprendizaje, pues su dificultad radica en que son idiosincráticas. Por estar fijadas en la norma, cada comunidad elige, establece y fija por el uso sus propias combinaciones que pasan a ser distintivas de ese grupo de hablantes. En este sentido, Higueras García (2006, p. 72) considera el desconocimiento de las restricciones combinatorias de las palabras en la LE como la barrera que separa al nativo del estudiante de esa lengua que, al realizar la traducción literal de las colocaciones a partir de su lengua materna, tiene dificultades y hace selecciones equivocadas en su producción oral y escrita.

En una colocación podemos identificar una base, que es semánticamente autónoma, y un colocativo o colocado. La base selecciona un colocativo y le atribuye un significado presente únicamente en coocurrencia (CORPAS PASTOR, 1996). De acuerdo con Hausmann (1998):

Podemos, por tanto, decir que la colocación es una relación orientada y que sus dos constituyentes tienen un estatuto semiotáxico distinto. Uno, el constituyente caracterizado, juega el papel de núcleo, semiotáxicamente autónomo, independiente (yo le llamo base de la colocación). El otro, el constituyente caracterizante, juega el papel de satélite, semiotáxicamente dependiente (yo le llamo colocativo) (HAUSMANN, 1998, p. 61). ${ }^{7}$

Aunque por su significado literal son fáciles, en general, de entender, el aprendiente de ELE, nativo de portugués, presenta dificultad en su uso. Precisamente

\footnotetext{
${ }^{7}$ Texto original: “Podemos, xa que logo, dicir que a colocación é unha relación orientada e que os seus dous constituíntes teñen un estatuto semiotáxico distinto. Un, o constituínte caracterizado, xoga o papel de núcleo, semiotaxicamente autónomo, independente (eu chámolle base da colocación). O outro, o constituínte caracterizante, xoga o papel de satélite, semiotaxicamente dependente (eu chámolle colocativo)."
} 
porque son transparentes o parcialmente transparentes, tiende a traducirlas del portugués al español, sin pensar que las opciones combinatorias en español puedan ser otras. Esto se debe, al menos en parte, porque este tipo de combinación no se trabaja específicamente en el proceso de enseñanza y aprendizaje de la lengua española para hablantes del portugués en Brasil y los materiales didácticos tampoco lo incluyen, como ya explicamos anteriormente.

El alumno no presenta dificultades en la comprensión de la colocación, pues si conoce las palabras separadamente entiende el conjunto. El problema reside en la producción y a partir del desconocimiento del aprendiente de que algunas palabras aparecen en el discurso relacionadas con otras - lo que Corpas Pastor (1996) llamó de restricción combinatoria-, esto le hace quedar excluido de la "complicidad lingüística" de los hablantes nativos (CASTILLO CARBALLO, 2000, p. 269).

Las colocaciones se pueden dividir en gramaticales o léxicas. Las propuestas de enseñanza de la lengua española se han encargado de estudiar las colocaciones gramaticales como "consistir en" (KOIKE, 2000, p. 2) compuestas de una construcción de verbo con complemento preposicional de régimen. Este proyecto abarcará las colocaciones lexicales adoptando la propuesta de Koike (2000, p. 17- 22) que las define según sus aspectos formales y semánticos:

Características formales:

- Coocurrencia frecuente: no todas las combinaciones de alta frecuencia son colocaciones léxicas. Koike (2000, p. 19) introduce aquí el enfoque estadístico y considera que "cuando el porcentaje de coocurrencia de dos unidades léxicas es superior al 20\%, puede haber una cohesión sintáctica o léxica".

- Restricciones combinatorias: provienen del uso tradicional de una lengua y tienen un carácter arbitrario. Aguilar-Amat Castillo (1993, p. 267) explica que “cada lengua ha desarrollado un tipo distinto de asociaciones en virtud de su 
realidad histórica, ambiental, cultural y lingüística". La lengua española y la lengua portuguesa tienen los verbos tomar y pegar, pero el sustantivo ómnibus elige el verbo tomar en español (tomar un ómnibus) y el verbo pegar en portugués (pegar o ônibus). Lo mismo ocurre con recibir y ganar. En español, el sustantivo regalo elige recibir (recibir un regalo) y en portugués se usa ganar (ganhar um presente).

- La composicionalidad formal: permite cierta flexibilidad combinatoria, morfológica y sintáctica al sustituir alguno de los componentes como en resolver o solucionar una duda; violar o transgredir o vulnerar las normas, o al modificarla incluyendo un adjetivo como dar una conferencia corta o dar una conferencia larga.

Características semánticas:

- Vínculo de dos lexemas: es el vínculo establecido a partir de sus significados léxicos que permite cambios de categoría gramatical: discutir acaloradamente /discusión acalorada; luchar encarnizadamente / lucha encarnizada.

- Tipicidad de la relación: el sustantivo piano (base de la colocación) establece una relación típica como instrumento musical con tocar y afinar (colocativos). Sin embargo, limpiar el piano y comprar el piano son combinaciones libres.

- Precisión semántica de la combinación: el nativo de español conoce qué palabras se usan, por ejemplo, para decir 'cubrir el cuerpo con una ropa' y elige la colocación ponerse la ropa. El alumno brasilero que estudia español probablemente diría: vestir la ropa. El verbo vestir existe en español, pero no se usa en este caso.

A partir de la categoría gramatical y de la relación sintáctica entre los elementos que constituyen una colocación, es posible establecer una taxonomía de estas combinaciones. Nuestro trabajo propone la elaboración de un diccionario con 
colocaciones simples constituidas por un sustantivo + verbo, a partir de las propuestas de Corpas Pastor (1996, p. 67-76) y Koike (2000, p. 41-42).

Las colocaciones de sustantivo y verbo pueden estar estructuradas de la siguiente forma de acuerdo con la función sintáctica que realice el sustantivo:

- Sustantivo(sujeto) + verbo: En este caso el sustantivo es el sujeto gramatical y se relaciona con verbos intransitivos o pronominales. Koike (2000, p. 44) explica “que la mayor parte de los verbos que indican fenómenos meterológicos y sonidos emitidos por animales constituyen colocaciones de este tipo".

Ejemplos: levantarse la niebla, ladrar el perro, latir el corazón, correr el rumor, cortarse la leche.

- Verbo + sustantivo(objeto): El esquema sintáctico es (sujeto) + verbo + sustantivo (complemento directo). Ningún verbo intransitivo está habilitado para formar colocaciones de este tipo. En general, son verbos transitivos directos formados por dos actantes: sujeto y objeto. Dentro de esta categoría se incluyen los verbos altamente polisémicos como dar, tomar, hacer, tener y poner.

Ejemplos: desempeñar un cargo, conciliar el sueño, acariciar una idea.

- Verbo + (...) preposición + sustantivo: El sustantivo núcleo del sintagma preposicional establece una combinación típica con un verbo. Estas colocaciones incluyen verbos transitivos, intransitivos o pronominales.

Ejemplos con verbos transitivos: sacar (a alguien) de un apuro, tomar (algo) a broma, llenar (a alguien) de esperanza.

Ejemplos con verbos intransitivos o pronominales: caer en desuso, venir con chismes, dejarse de rodeos.

Koike (2000) sostiene que las colocaciones sustantivo+verbo se encuentran siempre bajo el control de determinados esquemas sintácticos que proyecta el verbo. 
En cambio, de acuerdo con Írsula (1994), los sustantivos son considerados la base a partir de los cuales se determinan los verbos que se van a utilizar. Sin embargo, este autor (1994) también afirma que el verbo puede determinar el sustantivo que lo acompaña y que esa elección depende de la semántica del verbo y de lo que es usual y tradicional en la colectividad de hablantes de una lengua. Por ejemplo, el verbo comer, en español, se usa para animales y para personas, en cambio, para plantas se usa alimentar, en español, las plantas se alimentan.

A continuación, pretendemos clarificar un aspecto lingüístico pragmático de nuestro trabajo referente a la proximidad terminológica-conceptual entre lo que entendemos por colocación y por restricción léxica. Algunos autores justifican la no inclusión de ciertas combinaciones por atribuirles restricciones semánticas que no proporcionan información lingüística. Sánchez Rufat (2010) considera que la combinación reservar una habitación no es una colocación, sino una restricción sistemática extralingüística, "su frecuencia de coaparición no proporciona información lingüística, tan sólo la frecuencia con la que se realizan estas acciones" (SÁNCHEZ RUFAT, 2010, p. 301).

En consecuencia, reservar una habitación es más frecuente que reservar una mesa. En portugués decimos reservar um quarto. En la variedad diatópica del Río de la Plata, cuando una persona quiere hospedarse en un hotel, reserva una habitación y esa es la combinación que se espera que un hablante utilice. En ese sentido, se trata de una información lingüística semántica porque se reserva una habitación y no un cuarto, ni un aposento, ni una alcoba que son sinónimos de cuarto. El verbo reservar (la base) selecciona el sustantivo habitación (el colocativo) y no otro, porque habitación es el alojamiento que hay en los hoteles.

Sostenemos que la combinación reservar una habitación denota entre sus componentes una relación típica con un grado de fijación que establece cierto grado 
de restricción combinatoria; consecuentemente, las palabras poseen un vínculo semántico y por ese motivo inferimos que se trata de una colocación.

A continuación, explicaremos sobre nuestro proyecto de un diccionario de colocaciones.

\section{Diccionario de colocaciones}

Los estudiantes producen las colocaciones de la legua materna de forma mecánica, pero según nuestra experiencia en la LE, uno de los errores interlinguales más comunes es el de la sustitución de la base o del colocativo de la colocación (en nuestro caso, el sustantivo o el verbo) por el usado en la lengua materna de los aprendientes.

Vázquez (1999, p. 25) observa que analizar errores sirve "para tener un conocimiento más profundo del proceso de aprendizaje y, por lo tanto, tener pautas para enseñar mejor". Cuando los alumnos quieren producir una colocación y desconocen una de sus partes transfieren la que se usa en su lengua materna a la LE que están aprendiendo. Nuestra práctica en la enseñanza de ELE en Brasil nos permite conocer una relación de colocaciones de verbo + sustantivo correspondientes al nivel inicial, según el MCER (CONSEJO DE EUROPA, 2002), en las que el alumno generalmente comete este error interlingual. El alumno tira la ropa y $\underline{\text { escova }}$ los dientes en lugar de sacarse la ropa y lavarse los dientes. Al analizar estas estructuras, vislumbramos la posibilidad de reunir estas colocaciones divergentes dentro de un diccionario con la finalidad de subsanar o hasta evitar este fenómeno lingüístico.

Molina García (2006) considera que el diccionario debe tener un fin didáctico y que el objetivo principal es el aprendiz. En ese sentido el diccionario pasa a ser una herramienta pedagógica para auxiliar al alumno. Por su parte, Fernández López (1995, p. 213) puntualiza que "la acción didáctica debe llevar al aprendiz a ser consciente del problema, para ponerlo en situación de analizar la causa y reorganizar sus hipótesis". 
De este modo, si queremos que el alumno evite la transferencia colocacional, una de las posibilidades es recurrir a un diccionario apropiado como ayuda y así evitar que los errores de las colocaciones se fosilicen y continúen apareciendo en niveles avanzados.

Las colocaciones, a veces, figuran en los diccionarios de la lengua, pero en general, en ese tipo de diccionario no se obtiene información adecuada sobre cómo se combinan las palabras. En palabras de Higueras García (2004, p. 482) “a pesar de no ser su objetivo principal, se pueden inferir algunas colocaciones a partir de ejemplos, del contorno o de la propia definición, si bien no siempre se aborda este tema con la sistematicidad deseada". En la opinión de Maldonado (2017), no se debe proporcionar información exhaustiva sobre las combinaciones de palabras en los diccionarios generales semasiológicos. Esto no se debe a que su diseño no lo permita, sino porque considera que los usuarios no los consultan en busca de este tipo de información.

En contraposición, los diccionarios de colocaciones ofrecen información detallada sobre ese asunto. Actualmente, en lengua española hay diccionarios especializados, llamados de combinatorios que contienen colocaciones; sin embargo, en ellos no se aplica el concepto clásico de colocación. Para Bosque (2010, p. XIX), la expresión diccionario combinatorio "es el puente que une la lexicografía con la gramática; el análisis de las palabras y el estudio de las formas en que se combinan". Son diccionarios que, además de colocaciones, ofrecen las restricciones semánticas que sufren las palabras a partir de sus relaciones.

Dentro de los diccionarios combinatorios en papel que incluyen las colocaciones podemos citar REDES Diccionario combinatorio del español contemporáneo (BOSQUE, 2010) que abarca combinaciones de palabras de acuerdo con su significado y ha sido elaborado a partir de un corpus de 250 millones de palabras provenientes de textos periodísticos. En cuanto a las combinaciones, Bosque (2010, p. LXX) explica que “las combinaciones contenidas en las clases léxicas pretenden ser representativas, 
como se dijo, pero no exhaustivas" por lo que se han elegido sólo algunas de las formas para figurar en el diccionario. "Redes no pretende proporcionar paradigmas completos —objetivo prácticamente inalcanzable-, sino definir y ejemplificar paradigmas representativos de las combinaciones léxicas" (BOSQUE, 2010, p. LXV). De esto se entiende que las palabras que aparecen en el diccionario pueden ser sinónimos, hipónimos o hiperónimos de otras formas, pero consideradas por los autores como las más representativas lingüísticamente. En cuanto a la frecuencia, una combinación cuyo uso no sea frecuente puede ser natural en la lengua, como por ejemplo, "albergar esperanzas" que es una colocación natural, pero no tan frecuente como "tener esperanzas". La frecuencia es un concepto estadístico, en cambio, la naturalidad es un concepto lingüístico y el diccionario Redes da preferencia a la naturalidad cuando estas dos informaciones no coinciden (BOSQUE, 2010).

También mencionamos el Diccionario combinatorio PRÁCTICO del español contemporáneo, las palabras en su contexto (BOSQUE, 2011) que tiene una estructura más didáctica que Redes por lo que se considera más accesible. De acuerdo con Barrios Rodríguez (2008), este último es una versión más simple que Redes, pero al mismo tiempo más amplia y útil especialmente para los estudiantes de ELE.

En cuanto a los diccionarios en línea podemos citar el Diccionario de colocaciones del español (DICE) donde la unidad lexicográfica (base de la colocación) incluye todas las informaciones relacionadas con las colocaciones en las que esta aparece, pero que se limita, por el momento, al campo semántico de los nombres de sentimiento y el Diccionario de Aprendizaje de Español como Lengua Extranjera (DAELE) que incluye colocaciones a partir de 363 verbos (sin nombrarlas como tales) y ofrece información detallada y ejemplos auténticos para estudiantes de nivel avanzado. Estos diccionarios son muy completos y ofrecen una detallada información; sin embargo, no responden a las necesidades de los alumnos de nivel 
inicial que buscan un diccionario simple de manejar y con información clara sobre los componentes de las colocaciones divergentes.

En relación con los diccionarios de colocaciones bilingües, Corpas Pastor (2017) observa la ausencia de un diccionario de colocaciones bilingüe Inglés-Español, siendo que también llamamos la atención sobre la falta de un diccionario de colocaciones bilingüe Portugués-Español, ya que existen actualmente diccionarios de colocaciones Inglés-Japonés, Inglés-Ruso, Alemán-Ruso, etc. (CORPAS PASTOR, 2017).

Para Hernández (2008), es necesario un tratamiento lexicográfico específico de las unidades léxicas pluriverbales, y en particular de las colocaciones, porque cuando se introduce la Fraseología, se trabaja en los diccionarios con cuestiones pragmáticas de significativa importancia, visto que el objetivo principal de estos diccionarios es desarrollar la competencia comunicativa de usuarios no nativos.

En este sentido la frecuencia entre los componentes de la combinación es un concepto muy explotado para corroborar la presencia de una colocación. Por otro lado, también la frecuencia de la colocación, de acuerdo con Torner, Bernal (2017) es un criterio que lleva a su selección, y esto ocurre porque colocaciones infrecuentes generalmente son poco útiles para el alumno.

Koike (2000, p. 17) empero puntualiza que "la coocurrencia frecuente de dos unidades léxicas es una de las características más importantes de la colocación", pero con la salvedad de que existen combinaciones de alta coocurrencia que no son colocaciones léxicas y unidades léxicas de baja frecuencia que son combinaciones típicas como abrocharse el cinturón que es una colocación que siempre aparece como aviso en el avión antes de despegar.

Alonso Ramos (2010) defiende una postura práctica en la que se debe considerar las necesidades del aprendiz de español como L2. Por lo tanto, se debe incluir en el diccionario lo que el usuario precisa. Alonso Ramos (ídem) explica que las 
colocaciones no tienen el mismo grado de fijación, de transparencia semántica o de idiosincrasia, pero que lo primordial es resolver las dudas del usuario.

Para Hernández (2008, p. 29), “la perspectiva lingüística, cultural y pragmática de la lengua de origen del estudiante" es lo que se debe tener en cuenta y esto es todo un reto en la elaboración de diccionarios. Concordamos con Hernández (ídem) en que se deben elaborar los diccionarios de acuerdo con la lengua materna de los estudiantes, tomando en cuenta su singularidad. Especializar el diccionario de acuerdo con las dificultades específicas de los alumnos, según su lengua de origen, es productivo en el aprendizaje. En consecuencia, en nuestro caso, no consideramos necesario que figuren las colocaciones iguales entre ambas lenguas, sino únicamente las divergentes, pues es en ellas que reside la mayor dificultad de los aprendientes.

De acuerdo con Hernández (2008),

Sigue siendo un objetivo fundamental de la Lexicografía Didáctica la realización de investigaciones y experiencias que tengan en cuenta la perspectiva del destinatario del diccionario. Es preciso indagar más, por ejemplo, en las necesidades de los estudiantes de español como lengua no materna. Y habrá que determinar si estas demandas cambiarán al variar la lengua de procedencia de los aprendices (HERNÁNDEZ 2008, p. 27).

Welker (2008, p.21) define los diccionarios pedagógicos como un tipo de obra que "planea tener en cuenta las necesidades lingüísticas y habilidades (y por lo tanto también las dificultades) de los aprendizes de lenguas" ${ }^{\prime}$.

En este sentido:

Los diccionarios comunes proporcionan información sobre los elementos léxicos de manera poco didáctica (por ejemplo, las definiciones son complicadas, y otras informaciones se dan de manera confusa), por lo que los usuarios tienen dificultad para entenderla. Ya

\footnotetext{
${ }^{8}$ Texto original: "[...] eles pretendem levar em conta as necessidades linguísticas e as habilidades (e, portanto, também as dificuldades) dos aprendizes de línguas".
} 
los diccionarios pedagógicos pretenden ser más didácticos. Mientras el adjetivo pedagógico — en lexicografía - se refiere a un tipo específico de diccionarios (aquellos que se destinan a los estudiantes de idiomas), didáctico debería sólo usarse para hablar de la manera en la que se proporcionan las informaciones (WELKER, 2008, p. 21-22) . $^{9}$

En consecuencia, esperamos que el diccionario pedagógico de colocaciones sea didáctico en la concepción de Welker (2008) para que el usuario alcance su objetivo al consultarlo.

Cabe señalar que el aporte de las nuevas tecnologías, en especial las informáticas se han vuelto vitales, pues los alumnos, en general cada vez más, cuentan con las herramientas necesarias para su uso. De acuerdo con Cassany (2012) contar con un portátil o instalar wifi en las aulas de una escuela no es suficiente, es necesario modificar las prácticas educativas. Se trata de realizar una "práctica cognitiva y social de ejecutar esas potencialidades en contextos reales y significativos, hasta el punto de poder apropiarnos de esas herramientas y de convertirlas en instrumentos básicos para nuestra vida" (CASSANY, 2012, p. 41-42). Los alumnos ya incorporaron esta tecnología en su vida social, ahora es indispensable que cuenten con estos recursos en su vida educativa. Esta tecnología, como Cassany (2012) predice, se volverá cada vez más inteligente permitiendo otras funciones como la posibilidad de distinguir formas diatópicas. Maldonado (2017) añade que la respuesta a los usuarios de los diccionarios ya no se hace por medio del papel y que se observa un cambio en los métodos de trabajo en la elaboración de los diccionarios con la inclusión de ediciones digitales basadas en bases de datos.

\footnotetext{
${ }^{9}$ Texto original: “Os dicionários comuns fornecem as informações sobre os itens lexicais de forma pouco didática (por exemplo, as definições são complicadas, e outras informações são dadas de maneira confusa), de sorte que os usuários têm dificuldade em compreendê-las. Já os dicionários pedagógicos pretendem ser mais didáticos. Enquanto o adjetivo pedagógico —em lexicografia—se refere a um tipo específico de dicionários (aqueles que se destinam a aprendizes de línguas), didático deveria ser empregado apenas para falar da maneira pela qual são fornecidas as informações".
} 
Teniendo todo ello en cuenta concordamos con Molina García (2006, p. 354) en que "no cabe pensar en un diccionario que no tenga un fin didáctico claro, por lo que todos los avances realizados en fraseografía han de tener como objetivo principal el aprendiz de lenguas". A seguir presentamos nuestra propuesta de diccionario.

\section{Propuesta de elaboración de un diccionario de colocaciones}

Esta propuesta está dirigida a un público meta de alumnos brasileros de lengua española, tanto de curso libre como de la enseñanza regular, que esté cursando los niveles iniciales. Se compone de colocaciones en lengua española de sustantivo +verbo, con o sin preposición, a partir de la entrada del sustantivo y con su equivalente en la lengua portuguesa. Las colocaciones seleccionadas poseen el siguiente rasgo en común, presentan divergencias entre el español y el portugués. Como ya se ha apuntado anteriormente, colocaciones iguales en ambas lenguas no figurarán en el diccionario. Esta obra tiene el objetivo de auxiliar a los aprendices que desconocen el verbo que acompaña al sustantivo dentro de la colocación, en sus producciones en lengua española. Elegimos el sustantivo como entrada porque la estructura verbo + sustantivo es una de las categorías más representativas en número e importancia comunicativa como señalamos al comienzo. (KOIKE, 2000, p.3). Pretendemos en una segunda etapa complementar este trabajo incluyendo también una sección a partir del verbo.

Conforme la tipología de Welker (2008) para la caracterización de un diccionario pedagógico, incluimos las propiedades de nuestro diccionario:

1) Especial (de colocaciones);

2) Destinado a hablantes no nativos (hablantes de portugués brasilero);

3) Bilingüe (español/portugués);

4) Electrónico (en línea). 


\subsection{Propuesta de macroestructura}

En esta sección trataremos sobre la selección de las colocaciones que integran este diccionario y su presentación a partir del sustantivo. Las entradas estarán dispuestas en orden alfabético por ser una de las formas más frecuentemente usada para ordenar los vocablos. Cuando sea necesario, se incluye referencia cruzada, indicada por 'ver', y así se le proporciona al alumno información sobre el sustantivo y sus sinónimos.

Molina García (2006) observa que seleccionar las UF que son convenientes para el alumno es una tarea subjetiva. En consecuencia, para equilibrar qué palabras deben figurar en el diccionario tomaremos en cuenta las necesidades de los alumnos de nivel inicial y seguimos los parámetros que presentamos en el apartado siguiente.

Como apoyo para el alumno, se presenta al inicio, un índice de las abreviaturas utilizadas en el material y una pequeña guía de usuario.

Dado que el diccionario se presentará en formato electrónico, por medio de una página web, se facilitará la consulta por parte de los aprendientes, pues permitirá primero el acceso a una lista de todos los sustantivos presentes en el diccionario y al detenerse en uno de ellos, remitirá a los verbos con los que ese sustantivo coaparece. Conforme el número de lemas vaya aumentando podremos adoptar otro formato

A continuación, explicamos los parámentos para seleccionar las colocaciones divergentes en lengua española de verbo + sustantivo.

\subsubsection{Para selección de las colocaciones de sustantivo + verbo}

El corpus de colocaciones de sustantivo+verbo en lengua española fue escogido a partir de producciones orales o escritas de estudiantes de los años finales de la Educación Básica del Colegio de Aplicação/UFRGS, de alumnos del segundo semestre del Núcleo de Ensino de Línguas em Extensão/UFRGS y extraídas de textos periodísticos de El País (Uruguay) y La Nación (Argentina). Se prefirió elegir 
colocaciones de acuerdo con la variedad diatópica del español de la región del Río de la Plata (Uruguay y Argentina), dado que el estado de Rio Grande do Sul (lugar de creación y práctica de este material) tiene un vínculo directo con estos países debido a su proximidad geográfica. La práctica de esta variedad diatópica favorece y auxilia en el desarrollo del intercambio económico y cultural con esta región del Plata, fenómeno que repercute también en otras regiones del Brasil. Por ese motivo, consideramos ventajoso que los alumnos practiquen esta variedad. Futuramente incluiremos otras variedades diatópicas de Hispanoamérica y España, visto que es imperioso desarrollar el plurilingüismo dentro de la lengua española en concordancia con la globalización que acerca las personas más allá de las fronteras geográficas.

Teniendo en cuenta el marco teórico, usamos los siguientes criterios para seleccionar las colocaciones:

- Estar formada por una base y un colocativo de verbo+sustantivo o sustantivo+verbo que puede estar acompañada por una palabra gramatical (preposición);

- La base o el colocativo de la colocación en lengua española (o ambos) debe ser divergente de una o ambas partes de la colocación en portugués brasilero;

- Presentar "cierta" fijación interna (tener ganas y no gana, sentir hambre y no hambres).

A partir de dichos criterios, llegamos a un conjunto de colocaciones que fueron analizadas en el Corpus del Español del Siglo XXI (CORPES XXI) y en el Diccionario REDES (BOSQUE, 2010). Elegimos el Diccionario REDES (Bosque 2010) por considerarlo el más completo en la actualidad. Sobre el conjunto seleccionado se aplicaron los siguientes criterios:

- Tener una frecuencia mínima de $20 \%$ en las coapariciones del Corpes XXI y de lo contrario, justificar su presencia; 
- Figurar en el Diccionario REDES (BOSQUE, 2010) y, de no estar incluída en dicha obra, justificar su presencia;

- Ser usada por los hablantes de la comunidad lingüística del Río de la Plata.

A continuación, presentamos el CORPES XXI (RAE) y el Diccionario REDES utilizados en la segunda etapa de selección de las colocaciones.

\subsubsection{El corpus del español del siglo xxi (corpes xxi)}

Se trata de un corpus formado por 225 millones de formas provenientes de 237.678 documentos comprendidos entre los años 2006 a 2015. El origen del 30\% de los textos corresponde a España y el resto, 70\%, proviene de América. El 90\% de los textos corresponde a la lengua escrita (libros 40\%, publicaciones periódicas 40\%, material de Internet 7,5\% y miscelánea 2,5\%) y el $10 \%$ a la lengua oral. El material que proviene de América se clasifica en zonas lingüísticas: Andina, Antillas (caribeña), Caribe continental, Chilena, Estados Unidos, México y Centroamérica y Río de la Plata. Los textos proceden de distintas áreas temáticas (actualidad, ocio y vida cotidiana, ciencias y tecnología, guión, novela, política, economía y justicia, salud, etc.).

Este corpus ofrece una herramienta que permite generar las coapariciones que son palabras que se combinan con el lema buscado con una frecuencia de 10 ocurrencias en adelante, basada en estadísticas generadas por programas informáticos. En la búsqueda de las coapariciones se pueden realizar tres filtros. El primero se refiere a la clase de palabra y, en este trabajo, buscaremos verbos (este corpus aún no incluye las formas pronominales) y sustantivos. El segundo filtro se refiere a la temática y para nuestra investigación elegimos el filtro "Todos" (que incluye temas de diversas áreas como Actualidad, Ciencias Sociales o Teatro). El último filtro se refiere al origen geográfico y, en una primera etapa de este trabajo, optamos por América y la zona lingüística del Río de la Plata debido a nuestra proximidad geográfica. La figura 1 muestra la herramienta y los filtros aplicados: 
Figura 1 - Coapariciones y filtros del CORPES XXI (RAE).

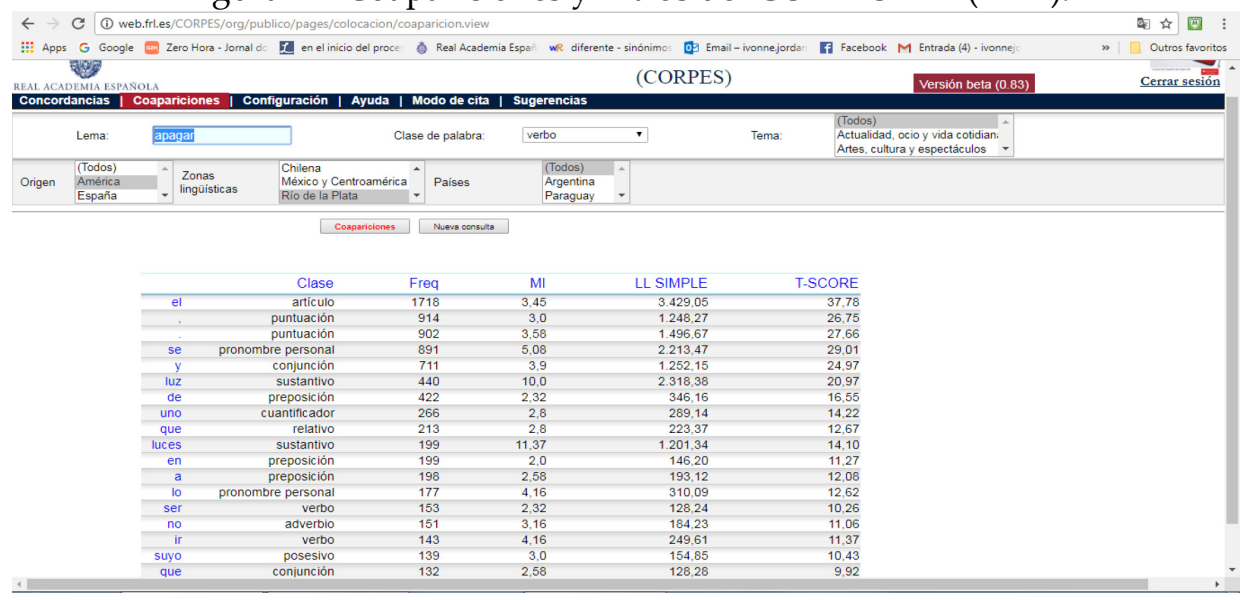

Fuente: Extraído de CORPES XXI - Coapariciones.

La Tabla 1, a continuación, muestra el análisis por medio de la frecuencia entre los componentes de la colocación. Como ya se ha apuntado anteriormente, la frecuencia no es un criterio excluyente en esta selección, por ese motivo justificamos los casos en que la frecuencia fue muy baja o no hubo frecuencia de coaparición.

Tabla 1 - Frecuencia de las colocaciones en el CORPES XXI.

\begin{tabular}{|c|c|c|}
\hline \multicolumn{3}{|c|}{ COLOCACIONES } \\
\hline VERBO & SUSTANTIVO & FRECUENCIA \\
\hline abrochar & Cinturón & $\begin{array}{l}13 \text { - es una colocación típica, porque a pesar de } \\
\text { la baja frecuencia es una combinación de } \\
\text { palabras que se usa en una situación específica }\end{array}$ \\
\hline apagar & Luz & 440 \\
\hline apagar & Celular & $\begin{array}{l}\text {--- el sustantivo celular es un vocablo } \\
\text { relativamente nuevo, por ese motivo el corpus } \\
\text { presenta pocas combinaciones }\end{array}$ \\
\hline apagar & computadora & 29 \\
\hline arreglar & problema & 27 \\
\hline bajar & Escalera & 223 \\
\hline buscar & solución & 167 \\
\hline dar & envidia & 20 \\
\hline desconectar & enchufe & $\begin{array}{c}\text {--- desconectar el enchufe significa desconectar } \\
\text { el cable del enchufe, la colocación conectar el } \\
\text { cable aparece con } 36 \text { de frecuencia }\end{array}$ \\
\hline despachar & valija & $\begin{array}{l}\text {--- se trata de una colocación típica, que se usa en } \\
\text { una situación específica, como justificamos } \\
\text { anteriormente }\end{array}$ \\
\hline esperar & turno & 77 \\
\hline guiñar & ojo & 120 \\
\hline hacer & cola & 136 \\
\hline
\end{tabular}




\begin{tabular}{|c|c|c|}
\hline mirar & película & 76 \\
\hline recoger & equipaje & $\begin{array}{c}\text {--- se usa en una situación específica, como } \\
\text { justificamos anteriomente. }\end{array}$ \\
\hline $\begin{array}{c}\text { rellenar (el verbo } \\
\text { que figura es } \\
\text { llenar) }\end{array}$ & formulario & 42 \\
\hline sacar & conclusiones & 153 \\
\hline sentir & nostalgia & 30 \\
\hline tener & gana & 849 \\
\hline tomar & avión & 58 \\
\hline
\end{tabular}

Fuente: La autora.

\subsubsection{REDES Diccionario combinatorio del español contemporáneo}

El diccionario Redes abarca combinaciones de palabras de acuerdo con su significado y ha sido elaborado a partir de un corpus de 250 millones de palabras provenientes de textos periodísticos de la prensa española y americana de los últimos años.

Bosque (2010, p. XVIII), coordinador de la obra, aclara que el significado de las palabras no puede estar separado de cómo se combinan, "sino que en gran medida se combinan de cierta manera porque expresan precisamente esos significados". El referido diccionario une la lexicografía con la gramática analizando las palabras y estudiando las formas con las que se combinan, fundamentándose en sus relaciones semánticas.

Es de conocimiento general que se puede romper un objeto (una mesa o un vidrio), pero también se rompe una promesa o un compromiso. Este es uno de los ejemplos que Bosque (2010) se vale para indicar la preferencia en usar, en las entradas, palabras abstractas y poco concretas porque son esos los vocablos que ayudan a los aprendientes a conocer el idioma. Concordamos con Bosque (2010, pág. CLIX) que "ningún corpus imaginable contendrá todos los datos que puedan considerarse representativos en un estudio lingüístico cualquiera suficientemente amplio".

Tras presentar algunos de los principios que orientan la elaboración del diccionario Redes, mostramos, a continuación, un ejemplo de cómo se realiza el 
análisis de las colocaciones seleccionadas en dicha obra. Para ello, en el Cuadro 1 incluimos estas colocaciones y usamos los símbolos: $\square$ y 冈 para confirmar la presencia o ausencia en el diccionario.

Cuadro 1 - Presencia o ausencia de las colocaciones en el diccionario Redes.

\begin{tabular}{|c|c|}
\hline COLOCACIÓN & COMENTARIOS \\
\hline abrocharse el cinturón囚 & $\begin{array}{l}\text { No figura en el diccionario, sin embargo se trata de una } \\
\text { combinación típica como justificamos anteriomente. }\end{array}$ \\
\hline apagar la luz $\square$ & \multirow{3}{*}{$\begin{array}{c}\text { El verbo apagar se combina con sustantivos que designan } \\
\text { aparatos o dispositivos eléctricos }\end{array}$} \\
\hline apagar el celular冈 & \\
\hline apagar la computadora $\boldsymbol{x}$ & \\
\hline \multicolumn{2}{|l|}{ arreglar el problema $\square$} \\
\hline bajar por la escalera冈 & En el diccionario figura la colocación bajar el escalón \\
\hline \multicolumn{2}{|l|}{ buscar una solución $\square$} \\
\hline \multicolumn{2}{|l|}{ dar envidia $\square$} \\
\hline desconectar el enchufe区 & $\begin{array}{l}\text { Es una colocación que se usa para explicar que se "saca el } \\
\text { enchufe del aparato donde esté conectado". }\end{array}$ \\
\hline despachar la valija冈 & $\begin{array}{l}\text { El verbo despachar admite sustantivos que designan lo que } \\
\text { se envía por correo o por otros medios }\end{array}$ \\
\hline \multicolumn{2}{|l|}{ esperar el turnoఐ } \\
\hline \multicolumn{2}{|l|}{ guiñar un ojo $\square$} \\
\hline \multicolumn{2}{|l|}{ hacer la cola $\square$} \\
\hline mirar una película $\otimes$ & En el diccionario figura la colocación ver una película \\
\hline \multicolumn{2}{|l|}{ recoger el equipaje $\square$} \\
\hline \multicolumn{2}{|l|}{ rellenar el formulario $\square$} \\
\hline \multicolumn{2}{|l|}{ sacar conclusiones $\square$} \\
\hline \multicolumn{2}{|l|}{ sentir nostalgia $\square$} \\
\hline \multicolumn{2}{|l|}{ tener ganas $\square$} \\
\hline tomar un avión $\square$ & \\
\hline
\end{tabular}

Fuente: La autora.

A partir de la aplicación de estos criterios, hemos reunido 224 colocaciones que serán las primeras a ser incluidas en el diccionario.

\subsection{Propuesta de microestructura}

En la microestructura se identifica el lema (sustantivo) de acuerdo con su género y número. Estas indicaciones se presentan en forma de abreviaturas cuyo significado se ha explicado al inicio del diccionario. La información del género es importante para 
que el alumno de nivel inicial perciba que el género de las palabras puede variar según la lengua. Incluimos la información sobre número, porque la colocación puede estar compuesta por un sustantivo en plural como lavarse los dientes.

A partir del sustantivo, se presentan las colocaciones de verbo + sustantivo y a seguir cada equivalente en la lengua portuguesa. En algunos casos, que se informa con la abreviatura ant. se incluye la colocación con el verbo que funciona como antónimo.

Este diccionario no comprende definiciones porque consideramos que el alumno parte de un sustantivo ya trabajado en la lengua española, pero carece de información sobre los verbos con los que este sustantivo compone la colocación. Por el momento, no colocaremos ejemplos para mostrar el uso de la colocación con frases extraídas del corpus usado, porque aún estamos verificando el formato y su utilidad. Pensamos en la posibilidad de que figuren ejemplos creados por los mismos alumnos y de esa manera, el mismo tenga un valor didáctico.

\subsubsection{Equivalencia}

Hernández (2008) reconoce la importancia de precisar no sólo cómo los diccionarios enseñan a los estudiantes, sino también cómo los estudiantes aprenden más cuando los utilizan. De acuerdo con Molina García (2006, p. 38) un diccionario bilingüe es aquel "que relaciona los vocabularios de dos sistemas lingüísticos diferentes" y ayuda al alumno en la recepción y producción de textos. Este autor (ídem) explica que hay diferencias en la información que el aprendiz recibe, ya sea para recepción o para producción de un texto y, por ejemplo, para producir un texto es vital el aporte de información clara sobre las colocaciones usuales que ayuden en la producción de LE. Molina García (2006, p.259) también observa que “a la hora de coordinar las unidades léxicas de la lengua de partida con las unidades de la lengua de destino [...], el equivalente no siempre llega a cubrir todas las propuestas semánticas, pragmáticas y comunicativas de la unidad de origen". "Lo que se conoce 
como equivalencia es más bien una correspondencia entre dos lenguas en términos de significado conceptual o proposicional, pero no equivalencia en todo y cada uno de los detalles" (MOLINA GARCÍA, 2006, p. 75). Nuestro objetivo es relacionar las colocaciones bilingües de forma sencilla y práctica, tomando en cuenta las necesidades de nuestros alumnos que buscan información para la producción. Por ese motivo, este diccionario registrará la equivalencia usual en la lengua portuguesa para auxiliar al alumno.

Corpas Pastor (2017) explica que puede ocurrir anisomorfismo cuando se parte de una colocación en la lengua de origen, pero en la lengua de destino es una combinación libre que no constituye una colocación como en el caso de inglés/español: do one's homework (inglés) /hacer los deberes (español). Esta autora (2017) aclara que como, en la actualidad, aún no se ha conseguido delimitar el concepto de colocación, la mayoría de los autores procura la coocurrencia como elemento diferenciador y se basa en la frecuencia, en la estadística, en la psicología o en la semántica para este fin. De acuerdo con Corpas Pastor (ídem) la equivalencia de las colocaciones acarrea dificultades debido a la arbitrariedad en su conformación, y esta es la razón por la que los diccionarios bilingües incluyen colocaciones como hacer los deberes/do one's homework. En este sentido, lo que buscamos es una obra que auxilie al alumno en sus producciones $\mathrm{y}$, por ese motivo, seleccionamos la colocación equivalente que consideramos más habitual en nuestros estudiantes.

\subsection{Muestra del diccionario}

Presentamos una muestra del diccionario pedagógico bilingüe de colocaciones de sustantivo +verbo.

\begin{tabular}{|c|}
\hline ABREVIATURAS \\
\hline 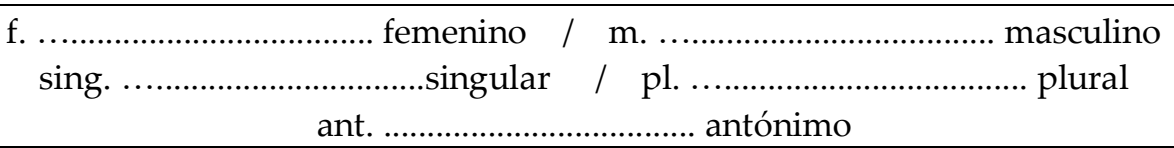 \\
\hline A \\
\hline
\end{tabular}




\begin{tabular}{|c|c|}
\hline años m. pl. & —cumplir años/fazer anos \\
\hline $\begin{array}{l}\text { auto } \mathrm{m} . \\
\text { ver coche }\end{array}$ & $\begin{array}{c}\text {-alejar el auto /afastar o carro } \\
\text { —adelantar a un auto / ultrapassar um carro } \\
\text { —arrancar el auto /ligar o carro } \\
\text { —arreglar el auto /consertar o carro } \\
\text { — prender el auto /ligar o carro }\end{array}$ \\
\hline $\begin{array}{l}\text { autobús m. } \\
\text { ver ómnibus }\end{array}$ & — tomar el autobús/pegar o ônibus \\
\hline avión m. & —tomar un avión/pegar um avião \\
\hline \multicolumn{2}{|r|}{$\mathrm{B}$} \\
\hline barba f. & —afeitarse la barba/fazer a barba \\
\hline \multicolumn{2}{|r|}{$\mathrm{C}$} \\
\hline casa $\mathrm{f}$. & $\begin{array}{l}\text {-alejarse de casa/afastar-se de casa } \\
\text { —arreglar la casa/arrumar a casa }\end{array}$ \\
\hline canción f. & $\begin{array}{l}\text { —escuchar una canción/escutar uma música } \\
\text { —oír una canción/ouvir uma música }\end{array}$ \\
\hline cara f. & - lavarse la cara/lavar o rostro \\
\hline castigo m. & -poner de castigo/botar de castigo \\
\hline celular $\mathrm{m}$. & $\begin{array}{c}\text { - prender el celularligar o celular ant.-apagar el celular/desligar o } \\
\text { celular } \\
\text { —estar en el celular/mexer no celular }\end{array}$ \\
\hline cerveza f. & — tomar una cerveza/beber uma cerveza \\
\hline cinturón m. & $\begin{array}{l}\text {-abrocharse el cinturón/apertar o cinto (en el avión) } \\
\text { —ponerse el cinturón/usar o cinto, colocar o cinto (en el auto/coche) }\end{array}$ \\
\hline cita f. & -marcar una cita/marcar um encontro \\
\hline $\begin{array}{l}\text { coche } \mathrm{m} . \\
\text { ver auto }\end{array}$ & $\begin{array}{c}\text {-alejar el coche/afastar o carro } \\
\text { —adelantar a un coche/ultrapassar um carro } \\
\text { —arrancar el coche/ligar o carro } \\
\text { —arreglar el coche/consertar o carro } \\
\text { — prender el coche/ligar o carro }\end{array}$ \\
\hline cohetes m. sing. & - tirar un cohete/soltar um foguete \\
\hline cola f. & -hacer la cola/fazer fila \\
\hline comida f. & - condimentar, aliñar la comida/temperar a comida \\
\hline computadora f. & $\begin{array}{l}\text { - prender la computadora/ligar o computador } \\
\text { ant.-_apagar la computadora/desligar o computador }\end{array}$ \\
\hline conclusiones f. pl. & —sacar conclusiones/tirar conclusões \\
\hline cordones m. pl. & $\begin{array}{l}\text {-atarse los cordones/amarrar os cadarços } \\
\text { ant.-_desatarse los cordones/desamarrar os cadarços }\end{array}$ \\
\hline cumpleaños m. & —estar de cumpleaños/fazer aniversário \\
\hline curso m. & $\begin{array}{c}\text {-hacer, realizar, asistir a un curso/fazer, frequentar um curso, } \\
\text { participar de um curso }\end{array}$ \\
\hline curva f. & - tomar la curva/fazer a curva \\
\hline \multicolumn{2}{|r|}{$\mathrm{D}$} \\
\hline dedos m. pl. & —chuparse los dedos/lamberse os dedos \\
\hline desuso $\mathrm{m}$. & —caer en desuso/tornar-se obsoleto \\
\hline dientes m. pl. & -lavarse los dientes/escovar os dentes \\
\hline & $\mathrm{E}$ \\
\hline
\end{tabular}




\begin{tabular}{|c|c|}
\hline escapada f. & -hacer una escapada/dar uma fugidinha \\
\hline enchufe $\mathrm{m}$. & —desconectar el enchufe/desligar a ficha \\
\hline envidia $\mathrm{f}$. & —dar envidia/fazer, dar inveja \\
\hline equipaje $\mathrm{m}$. & -recoger el equipaje/retirar a bagagem \\
\hline ensalada $\mathrm{f}$. & — condimentar la ensalada/temperar a salada \\
\hline escalera f. & —bajar la escalera/descer a escada \\
\hline examen $\mathrm{m}$. & -aprobar el examen/passar na prova \\
\hline éxito m. & -tener éxito/ter sucesso \\
\hline \multicolumn{2}{|r|}{ 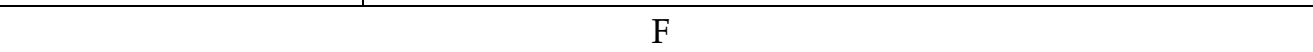 } \\
\hline formulario $\mathrm{m}$. & -rellenar el formulario/preencher o formulário \\
\hline fotocopias f. pl. & —sacar, hacer fotocopias/tirar, fazer xerox, fotocópias \\
\hline fotos f. pl. & —sacar fotos/tirar, bater fotografias \\
\hline fútbol m. & $\begin{array}{l}\text { —jugar al fútbol/jogar futebol } \\
\text { —practicar fútbol/treinar futebol }\end{array}$ \\
\hline \multicolumn{2}{|r|}{$\mathrm{G}$} \\
\hline ganas & -tener ganas/ter vontade \\
\hline \multicolumn{2}{|r|}{$\mathrm{H}$} \\
\hline hotel $\mathrm{m}$. & -alojarse en un hotel/hospedar-se num hotel \\
\hline \multicolumn{2}{|r|}{$\mathrm{I}$} \\
\hline impaciencia $\mathrm{f}$. & —esperar con impaciencia/aguardar com impaciência \\
\hline \multicolumn{2}{|r|}{$\mathrm{L}$} \\
\hline luz $\mathrm{f}$. & $\begin{array}{l}\text { —apagar la luz/desligar a luz } \\
\text { ant.-prender la luz/ligar, acender a luz }\end{array}$ \\
\hline \multicolumn{2}{|r|}{$\mathrm{M}$} \\
\hline mano $\mathrm{m}$. & —dar la mano/apertar a mão \\
\hline medidas m.pl. & —adoptar medidas/tomar providencias \\
\hline mentira f. & - decir una mentira/falar uma mentira \\
\hline molestia f. & —causar una molestia/causar um incômodo \\
\hline multa f. & -recibir una multa/ganhar uma multa \\
\hline \multicolumn{2}{|r|}{$\mathrm{N}$} \\
\hline nostalgia $\mathrm{f}$. & —sentir nostalgia/ter saudade \\
\hline \multicolumn{2}{|r|}{$\mathrm{O}$} \\
\hline ojo m. & —guiñar un ojo/piscar o olho \\
\hline $\begin{array}{l}\text { ómnibus m. } \\
\text { ver autobús }\end{array}$ & —tomar el ómnibus/pegar o ônibus \\
\hline \multicolumn{2}{|r|}{$\mathrm{P}$} \\
\hline parte f. & -formar parte/fazer parte \\
\hline película m. & —ver una película, mirar una película/assistir um filme \\
\hline pelo $\mathrm{m}$. & —aclararse el pelo/clarear o cabelo \\
\hline platos m. pl. & -lavar los platos/lavar a louça \\
\hline prisa f. & -tener prisa/estar com pressa \\
\hline problema m. & —arreglar el problema/resolver o problema \\
\hline puente $\mathrm{m}$. & -cruzar el puente/atravessar a ponte \\
\hline \multicolumn{2}{|r|}{$\mathrm{R}$} \\
\hline refresco $\mathrm{m}$. & $\begin{array}{c}\text { - tomar un refresco/beber um refrigerante } \\
\text {-tomar un refresco/pegar um refrigerante (com a mão) }\end{array}$ \\
\hline regalo $\mathrm{m}$. & -recibir un regalo/ganhar um presente \\
\hline reunión $\mathrm{m}$. & —aplazar la reunión/adiar a reunião \\
\hline
\end{tabular}




\begin{tabular}{|c|c|}
\hline ropa $f$. & $\begin{array}{l}\text { - ponerse la ropa/vestir, colocar a ropa } \\
\text { ant.—sacarse la ropa/tirar a roupa, as vestimentas }\end{array}$ \\
\hline \multicolumn{2}{|r|}{$\mathrm{S}$} \\
\hline situación $\mathrm{f}$. & —manejar la situación/lidar com a situação \\
\hline solución f. & -buscar una solución/procurar uma solução \\
\hline sueldo $\mathrm{m}$. & —cobrar el sueldo/receber o salário \\
\hline \multicolumn{2}{|r|}{$\mathrm{T}$} \\
\hline televisión & $\begin{array}{c}\text { - prender la televisión, tele/ligar a } T V \text { ant.—apagar la televisión, } \\
\text { tele/desligar a } T V \\
\text { ver, mirar la televisión, tele/assistir TV }\end{array}$ \\
\hline turno m. & —esperar el turno/esperar a vez \\
\hline \multicolumn{2}{|r|}{$\mathrm{U}$} \\
\hline uñas f. pl. & —comerse las uñas/roer as unhas \\
\hline \multicolumn{2}{|r|}{$\mathrm{V}$} \\
\hline valija f. & —despachar la valija/despachar a mala \\
\hline verdad f. & —decir la verdad/falar a verdade \\
\hline vistazo f & —echar un vistazo/dar uma olhada \\
\hline
\end{tabular}

\section{Conclusiones}

En este artículo destacamos la importancia de la Fraseología y de las colocaciones en especial, como piezas esenciales del acto comunicativo. En este sentido, en el contexto de enseñanza de ELE en Brasil, observamos que no se le presta especial atención pedagógica a las colocaciones divergentes entre ambas lenguas y por desconocimiento, los alumnos transfieren las colocaciones de su lengua materna a la lengua española. Por ese motivo, decidimos elaborar un diccionario de colocaciones de sustantivo+verbo divergentes entre el español y el portugués para auxiliar a los alumnos en sus niveles iniciales de aprendizaje.

Para ello, hemos revisamos el concepto de fraseología y de colocación, presentamos los distintos tipos de colocaciones e indicamos sus características. Enseguida, describimos nuestra propuesta metodológica, destacando la selección de la colocaciones que formarán parte del diccionario. Asimismo, mostramos los principios que guían su organización —usuario y función- los criterios que guiaron la selección de la macroestructura y una propuesta de microestructura con algunos ejemplos de colocaciones. Destacamos una vez más que listamos las colocaciones a 
partir del sustantivo en la variedad del Rio de la Plata; sin embargo, pretendemos también presentar las colocaciones a partir del verbo e incluir otras variedades diatópicas del español adecuando el formato a las necesidades del estudiante.

Pretendemos continuar investigando sobre las necesidades colocacionales de los alumnos brasileños de ELE, siempre buscando su desarrollo como usuario autónomo para que pueda servirse de este material como fuente de informaciones colocacionales.

\section{Referencias bibliográficas}

AGUILAR-AMAT CASTILLO, A. En torno a la combinatoria del léxico: Los conceptos de colocación e idiomatismo. In: VIDE, C. M. (Coord.). Lenguajes naturales y lenguajes formales. Actas del IX Congreso de Lenguajes naturales y Lenguajes formales, 1993, p. 267-272.

ALONSO RAMOS, M. No importa si la llamas colocación, descríbela. In: MELLADO, C. et al (ed.). Nuevas propuestas para el español y el alemán. Berlín: Frank \& Timme, 2010, p. 55-80.

BARRIOS RODRÍGUEZ, M. A. Diccionarios combinatorios del español: diferencias y semejanzas entre Redes y Práctico. In: El diccionario como puente entre las lenguas y culturas del mundo. Actas del II Congreso Internacional de Lexicografía Hispánica, 2008, p.197-203.

BOSQUE, I. REDES Diccionario combinatorio del español contemporáneo: las palabras en su contexto. Madrid: Ediciones SM, 2010.

BOSQUE, I. Diccionario combinatorio práctico del español contemporáneo. Madrid: Ediciones SM, 2011.

CASSANY, D. En_línea Leer y escribir en la red. Barcelona: Editorial Anagrama, 2012.

CASTILlO CARBALlO, M. A. Norma y producción lingüística: las colocaciones léxicas en la enseñanza de segundas lenguas. In: ¿Qué Español Enseñar? Norma y Variación Lingüística en la Enseñanza del Español a Extranjeros. Actas del XI Congreso Internacional de la ASELE, 2000, p. 267-272. 
COIMBRA, L.; CHAVES, L. S.; ALBA, J. M. Cercanía, Língua Estrangeira Moderna Espanhol, 7ํano. São Paulo: Editora SM, 2012.

CONSEJO DE EUROPA. Marco común europeo de referencia para las lenguas: aprendizaje, enseñanza, evaluación. Traducción del Instituto Cervantes. Madrid: Anaya, 2002.

CORPAS PASTOR, G. Manual de fraseología española. Madrid: Gredos, 1996.

CORPAS PASTOR, G. Collocations in e-bilingual dictionaries. From underlying theoretical assumptions to practical lexicography and translation issues. In: CASTELLS, S. T. Collocations and other lexical combinations in Spanish. Theoretical, Lexicographical and Applied Perspectives. Londres y New York: Routledge, 2017.

COSERIU, E. Lições de Linguística Geral. Tradução de Evanildo Bechara. Rio de Janeiro: Ao Livro Técnico, 1980.

Diccionario de Aprendizaje de Español como Lengua Extranjera (DAELE) Disponible en: http://www.iula.upf.edu/rec/daele/. Consulta: 27 de ene. 2018.

Diccionario de Colocaciones del Español (DICE). Disponible en: http://www.dicesp.com/paginas. Consulta: 27 de ene. 2018.

FERNÁNDEZ LÓPEZ, S. Errores e interlengua en el aprendizaje de español como lengua extranjera. Didáctica, №7, Servicio de Publicaciones UCM, Madrid, 1995, p. 203-216.

GONZÁLEZ REY, M. I. A fraseodidáctica e o Marco europeo común de referencia paras as linguas. Cadernos de Fraseoloxia Galega, Santiago de Compostela, № 8, 2006, p. 123-145.

HAUSMANN, F. J. O diccionario de colocacións. Criterios de organización. In: RUIBAL, X. F. (coord.). Actas do I COLOQUIO GALEGO DE FRASEOLOXÍA (1997). Santiago de Compostela: Centro Ramón Piñeiro para a Investigación en Humanidades, 1998, p. 63-81.

HERNÁNDEZ, H. Retos de la lexicografía didáctica española. Alicante: Biblioteca Virtual Miguel de Cervantes, 2008, p.22-32. 
HIGUERAS GARCÍA, M. Necesidad de un diccionario de colocaciones para aprendientes de ELE. In:_CASTILLO CARBALLO, M. A. (coord.) Las gramáticas y los diccionarios en la enseñanza del español como segunda lengua, deseo y realidad. Actas del XV Congreso Internacional de ASELE, Sevilla, 2004, p. 480-490

HIGUERAS GARCÍA, M. Estudio de las colocaciones léxicas y su enseñanza en español como lengua extranjera. Málaga: Secretaría General Técnica, ASELE, Colección Monografías № 9, 2006.

ÍRSULA, J. Entre el verbo y el sustantivo, ¿quién rige a quién? El verbo en las colocaciones sustantivo-verbales. In: ENDRUSCHAT, A. et al. (coord.). Verbo e estruturas frásicas. Actas do IV Colóquio Internacional de Lingüística Hispânica. Porto: Editora da Universidade de Porto, 1994, p. 277-286.

KOIKE, K. Colocaciones léxicas en el español actual: estudio formal y léxicosemántico. Madrid: Universidad de Alcalá, 2000.

LEWIS, M. The lexical approach. The State of ELT and a Way Forward. Londres: Language Teaching Publications, Thomson, 2002.

MALDONADO, C. Word combinations in general dictionaries. In: CASTELLS, S. T. Collocations and other lexical combinations in Spanish. Theoretical, Lexicographical and Applied Perspectives. Londres y New York: Routledge, 2017.

MOLINA GARCÍA, D. Fraseología bilingüe: un enfoque lexicográfico-pedagógico. Granada: Editorial Comares, 2006.

NAVARRO, C. Didáctica de las unidades fraseológicas. 2004. Disponible en: https://www.edinumen.es/index.php?option=com content\&view=article\&id=93\&cati $\underline{\mathrm{d}=13 \& I t e m i d=51}$. Consulta: 20 de nov. 2017.

REAL ACADEMIA ESPAÑOLA. Banco de datos: Corpus del Español del Siglo XXI (CORPES XXI). Disponible en: http://www.rae.es. Consulta: 5 de dic. 2017.

RUIZ GURILLO, L. Aspectos de fraseología teórica española. Anejo no XXIV de la Revista Cuadernos de Filología Departamento de Filología Española. Facultat de Filologia. Valencia: Universitat de València, 1997.

SÁNCHEZ RUFAT, A. Apuntes sobre las combinaciones léxicas y el concepto de colocación. Anuario de Estudios Filológicos, vol. XXXIII, 2010, p. 291-306.

VÁZQUEZ, G. ¿Errores? ¡Sin falta! Madrid: Edelsa, 1999. 
TORNER, S., BERNAL, E. Collocations in learner's dictionaries. In: CASTELLS, S. T. Collocations and other lexical combinations in Spanish. Theoretical, Lexicographical and Applied Perspectives. Londres y New York: Routledge, 2017.

WELKER, H. A. Panorama General de la Lexicografía Pedagógica. Brasília: Thesaurus, 2008. 